\title{
Identification and analysis of geotechnical risks in the conditions of flooding of the remaining gaps
}

\author{
Izabela Maria Apostu ${ }^{1, *}$, and Florin Faur ${ }^{1}$ \\ ${ }^{1}$ University of Petrosani, Faculty of Mining, Department of Environmental Engineering and Geology, \\ University Street, no. 20, Romania
}

\begin{abstract}
Controlled flooding of the remaining gaps of former quarries (especially lignite quarries) and the formation of lakes that can take different uses is one of the ways of recovering and rehabilitating degraded mining lands which offer opportunities for sustainable development of a mining region. The advantages of such a solution are multiple, starting from the restoration of biodiversity, to economic and social benefits. Basically, several flooding techniques are known, but depending on the geological, geotechnical, hydrological and hydrogeological conditions characteristic for a particular region, these techniques must be adapted to the risks that may arise before, during and after flooding the remaining gap. Most of the times, the risks are of geotechnical nature and arise as a result of the interaction between the rocks and the mixture of loose rocks that form the final slopes and the dump with water. The paper is part of an extensive research, which is carried out under the concrete conditions of the remaining gaps in the Rovinari mining basin, and essentially aims at: identifying the main categories of geotechnical risks that can occur under the given conditions, determining the triggering factors, to produce negative geotechnical phenomena and their effects, as well as to identify the main measures to avoid them.
\end{abstract}

\section{Introduction}

Unlike the previous years, when the common practice in Romania was the abandonment of the mining perimeters at the end of the activity, today there is more emphasis on the recovery and reintegration of degraded lands into the landscape. Moreover, the degraded lands and the remaining gaps of the former lignite quarries can be rehabilitated, thus providing the former mining regions with many sustainable development opportunities with environmental, human health and safety benefits, the local economy and the well-being of local communities saddle.

Under the flooding of the remaining gaps of former quarries, there are a number of risks that may occur from a geotechnical point of view as a result of the interaction of the water with the rocks that form the final slopes. Water is one of the main causes of land loss, as it

*Corresponding author: izabelamaria.nyari@yahoo.com 
causes worsening of rock strength. The presence of water in the rock influences the state of unitary effort by: variation of the humidity of the rocks and modification of their geotechnical characteristics, the manifestation of the water pressure in the pores in the saturated conditions, the manifestation of the hydrodynamic pressure under the formation of the aquifers currents, the manifestation of the sufosional or liquefaction phenomena, erosion due to superficial leakage or wave action.

An example of negative geotechnical phenomena can be given at European level, but there are many more situations, with or without material or human damage. Germany is one of the countries that has encountered numerous geotechnical problems, but it is also one of the best examples of good practices of rehabilitation of areas affected by negative geotechnical phenomena. In 2009, in the city of Nachterstedt, there was a landslide at one of the final slopes of the former lignite quarry. The quarry was flooded after it's closure (1991) forming the Concordia artificial lake. It resulted in the destruction of some buildings, of natural objectives in the area and three people lost their lives. The main cause was the heavy rains that caused a significant increase in the groundwater level relative to the water level in the lake. There have been several works to restore the balance of the slopes. A measure of increasing the stability reserve was additional flooding and the rise of the water level in the lake by about $18 \mathrm{~m}$. [1]

The Law no. 575/2001 regarding the "Plan of the national territory development", the Fifth section - Areas of natural risks" imposes elaboration of landslide hazard maps in digital format to cover the whole Romanian territory. This program is in the initial phase of development and such maps issued since the beginning of 2004. The Law no. 575/2001 deals with "risk zones" and includes the presentation of the zones prone to landslides. [2]

Risk/hazard maps are particularly useful tools and can be developed as needed.In the case of remaining gaps in order to reduce and even eliminate geotechnical risks, it is important to know the characteristics of the site, such as geology and hydrogeology, geotehnic characteristics of the rocks. They allow the establishment of optimal methods for the recovery and rehabilitation of degraded mining lands, reuse directions and the determination of the optimal location of the objectives required for the reintegration of lands into the landscape. Depending on them, the flooding of the remaining gaps can be controlled flooding by establishing appropriate flooding techniques.

\section{The main categories of geotechnical risks and triggering factors}

Since geotechnical phenomena can have devastating effects, it is necessary to monitor the evolution of deformations preceding the landslides, factors and causes that influence the occurrence of geotechnical phenomena and prevent them by applying the appropriate measures to increase stability.

The presence of discontinuities such as cracks, fissures, stratification and changes resulting from erosion, sufosis, liquefaction or surface or deep sliding phenomena affect the strength characteristics of the rocks and implicitly of the rock massifs. [3]

According to the literature, the main geotechnical risks that may occur during the flooding of the remaining gaps are: the risk of sliding of the in-situ slopes, the risk of liquefaction of the sterile rocks from the inner dump, the risk of occurrence of sufosis phenomena, other types of negative geotechnical phenomena (erosion, abnormal settlement of the rocks). [3, 4, 5]

Under the influence of various external or internal factors, whether natural or artificial, the stability of the slopes is endangered by the destruction of the balance of the sliding forces and resistance forces from the rock's massifs. According to the literature [3], the factors influencing the stability of the slopes can be grouped in 6 categories: 
1. Geological and hydrogeological factors - it refers to the geological structure of the region, the nature of rocks, the presence of stratification surfaces, the presence of fissures, cracks etc. and to the presence of aquifer formations in the rock structure.

2. Mechanical and geomechanical factor - it refers to surface morphodynamic phenomena dependent on the nature and strength characteristics of the rocks.

3. Anthropogenic factors (technogens) - it refers to the morphological, structural or resistance changes of rocks as a result of anthropogenic activities.

4. Hydro-meteorological and climatic factors - it refers to the presence and intensity of precipitation, freeze-thaw phenomena, temperature variations, the presence of drought, the contraction-swelling phenomenon, etc.

5. Seismic Factor and Vibrations - resulting from the earthquakes or from the transport of machinery, blasting explosions, accidental explosions, traffic, etc.

6. The biotic factor - it refers to the presence of vegetation on slopes. Generally, it has a positive effect by anchoring rocks with roots, but vegetation can also have a negative effect as a result of overloading.

Water action plays an important role in triggering and evolving landslides, being the main cause of negative geotechnical phenomena. Cumulative with the influence of other factors of influence (frost-thaw, rock alteration, zone tectonics, zone seismicity, explosioninduced vibrations, machine traffic, excavations and overburden), there are important changes in the geotechnical characteristics of the rocks over time. These changes lead to the reduction of the rock resistance characteristics, and implicitly the reduction of the stability reserve of the rock massifs.

\section{Results and discussions}

The remaining gaps are often bordered by the final slopes of the quarry, and on the other side by the slopes of the inner dump. Unlike the rocks forming the final slopes of the quarry, the sterile rock in the dump are loose rocks, whose cohesion has been partially affected and pose a higher risk of slidding under the influence of various external factors.

\subsection{The mechanism of producing negative geotechnical phenomena}

Water is the main cause of occurence of negative geotechnical phenomena.

Underground waters have a negative effect on rock masses through the increasing of volumetric weight and the manifestation of pore water pressure and hydrodynamic pressure. Under the action of pore water pressure, the shear strength of the rocks is reduced as a result of the reduction in the strength characteristics. The hydrodynamic pressure acts in the direction of the underground flow lines and thus contributes to the increase of the sliding forces. Hydrodynamic pressure increases depending on the hydraulic gradient. [3]

\subsubsection{Landslides}

Landslides are geodynamic phenomena to restore the natural balance of slopes by slow, sometimes rapid, movement of part of their structure as a result of long-lasting physical and mechanical processes. [3-4]

The influence of many external or internal factors that occur over time on the rock masses leads to the formation of minimal resistance areas after which the landslides occur.

Sufosis phenomena, liquefaction, erosion, abnormal settlement may be the cause of large-scale landslides, as the geotechnical characteristics of the rocks and the state of rock massif/depozit efforts are changing considerably. Also, landslides can occur when the rock 
massif/deposit is created, under the influence of the factors mentioned, a surface of minimum resistance. Minimally resistant surfaces generally constitute sliding surfaces.

Based on the visual analysis performed in the perimeter of the North Pesteana quarry, there were sufosis zones, erosion zones, cracks and fissures, areas with superficial landslides. At the beginning of 2018, on the eastern slope of North Pesteana quarry, there was a landslide, which affected the road structure on the outskirts of the quarry, a road that serves the mining perimeter. The causes of this slide were the abundant precipitation and the major infiltrations from the Jiu River. Up to now, the changes and deformations occurring on the steps of the quarry and the inner dump in the North Pesteana mining perimeter did not affect the overall stability of the quarry or the inner dump, except the slide of the eastern slope of the quarry but could endanger the stability of the individual steps. [6]

\subsubsection{Sufosis phenomena}

Sufosis is a type of erosion that can occur in the case of open-pit exploitation and remaining gaps of the quarries and named also "underground erosion".

The sufosis phenomenon occurs under the action of groundwater, by:

- hydrodynamic sufosis, a process by which water trains fine particles of sandy rocks, under the action of hydrodynamic pressure, when the filtration speed exceeds the critical speed. Under these conditions the so-called "underground torrent" is formed.

- hydrochemical process, a process by which water dissolves and trains soluble substances that bind solid rock particles. Underground gaps that can be created can lead to the loss of the natural balance of rocks in the roof, the destruction of objectives in the area of influence and even the appearance of sliding phenomena.

In the North Pesteana mining perimeter it was observed that particular problems arise in the areas where natural drainage of groundwater occurs. According to the visual analysis performed in the North Pesteana minining perimeter, due to the natural drainage of the aquifer formations, through the slopes of the quarry, there was some sufosis phenomena which led to the occurrence of sufosis zones on the slopes of 1st and 2nd steps of the quarry (Figure 1). [6]

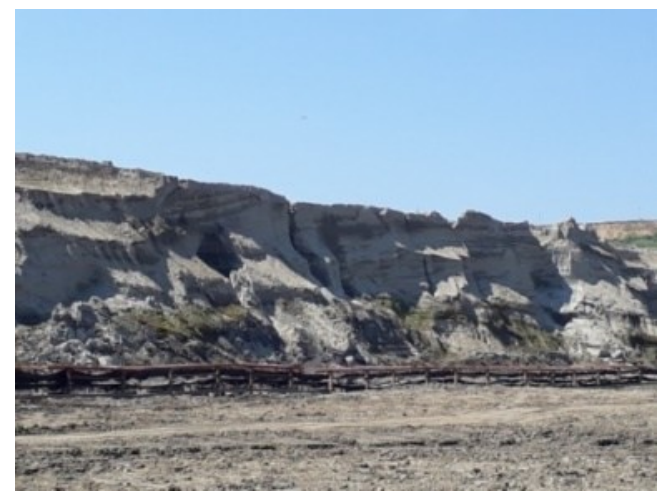

Fig. 1. Sufosis zones on the 1 st stept of the North Pesteana quarry

It is appreciated that when the dewatering works in the North Pesteana mining perimeter are stopped, the large inflow of underground water that will feed and contribute to the restoration of the aquifer resources and to the flooding of the remaining gap, may favor the manifestation of the sufosis phenomenon on a larger scale. If there were no sufosis phenomena until the complete flooding of the remaining gap of the North Pesteana quarry, 
the possibility of their manifestation in the future decreases, as the hydrostatic pressure will act on the final slopes of the remaining gap as a bearing prism.

\subsubsection{Liquefaction phenomena}

In the conditions of rocks saturation and the manifestation of pore water pressure, the liquefaction phenomenon may occur. With increasing pore water pressure, the rock granules are surrounded by a water film and and the rock particles are removed from each other. Thus, the material starts to flow, acting as a liquid. This phenomenon can be manifested in the conditions of loose rocks and with a large proportion of the sandy component and occurs especially in sterile dumps. Figure 2 (left) shows the stress conditions and the stresses in the vicinity of the pore space, where: $\sigma_{\mathrm{zz}}{ }^{\prime}$ - the effective vertical tension; $\sigma_{z z}$ - effective horizontal tension; $p_{w}$ - pore water pressure. [7]

Hydrostatic pressure reduces the effective stresses transmitted through particle contact. The total stresses, $\sigma$, consist of an effective stress component, $\sigma^{\prime}$ (which is removed by the skeleton of the rock) and the water pressure of the pores, $u$ (hydrostatic pressure). The relationship between total stresses, effective stresses and pore water pressure is shown in Figure 2 (right) and in relation 1. [7]

Thus, in the case of complete liquefaction, the effective stress value is $\sigma^{\prime} \approx 0$. When the pore water pressure reaches or exceeds the total horizontal stresses $\sigma_{\mathrm{xx}}$, but is still lower than the total vertical stresses $\sigma_{z z}$, partial liquefaction takes place.

Liquefaction can be hydrologically, mechanically or seismically stimulated. From a hydrological point of view, liquefaction problems can occur with the rise in groundwater level and pore water pressure due to the fall and infiltration of large amounts of precipitation water or hydrostatic elevation. Vibrations caused by earthquakes, explosions, heavy vehicles, ground and underground traffic and earthquake shocks may influence this phenomenon.
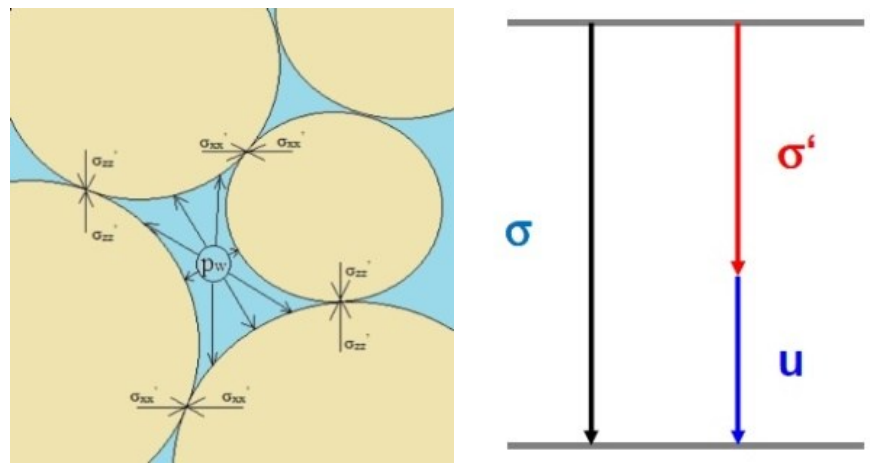

Fig. 2. Schematic representation of tensions in the vicinity of the pore space (left); Representation of the total stress in relation to the effective stress and the pore water pressure (right) [7]

$$
\sigma^{\prime}=\sigma-u
$$

In the case of the remaining gap of the North Pesteana quarry, the problem of liquefaction can occur especially in the slopes of the inner dump, but also in the in-situ slopes, in the sandy layers, during and even after the flooding of the remaining gap. From the point of view of mechanical and seismical influences, it was established that the vibrations resulting from the road and railway traffic, respectively the seismic activity in the area, independent of the presence and the action of the water, do not influence the occurrence of the liquefaction phenomenon. 
The lithological formations from the bed and the roof of the V-VIII lignite layers are constituted by a sedimentary rock complex belonging to the cretacic, paleogenic, neogen and quaternary. The waste rock layers consist mainly of a succession of clayey (30\%) and sandy rocks $(60 \%)$. [8]

According to the laboratory measurements carried out on 14 samples taken from different points in the inner dump of the North Pesteana quarry, it can be noticed that from the point of view of the granulometric composition (Table 1), the sterile material consists of important fractions of sand, which confirms once again the data in the reports drawn up by the specialized institutions.

Table 1. The granulometric composition of the rocks from the inner dump of North Pesteana quarry

\begin{tabular}{|l|l|l|l|l|}
\hline \multirow{2}{*}{$\begin{array}{l}\text { Sample } \\
\text { no. }\end{array}$} & \multicolumn{4}{|l|}{ The granulometric composition \% } \\
\cline { 2 - 5 } & Clay & Dust & Sand & Gravel \\
\hline PC1 & - & - & 100 & - \\
\hline PC2 & - & - & 100 & - \\
\hline PC3 & 7.5 & 27.5 & 65 & - \\
\hline PC4 & 33 & 17 & 50 & - \\
\hline PH1 & 24 & 28 & 42 & 6 \\
\hline PH2 & - & 38.5 & 61.5 & - \\
\hline PH3 & - & - & 91 & 9 \\
\hline PH4 & 20 & 43 & 27 & 10 \\
\hline PH5 & 10 & 55 & 33.5 & 1.5 \\
\hline PH6 & - & - & 99.5 & 0.5 \\
\hline PH7 & - & - & 73 & 27 \\
\hline PH8 & - & - & 78 & 22 \\
\hline PH9 & 41 & 52 & 7 & - \\
\hline PH10 & - & - & 89.5 & 10.5 \\
\hline
\end{tabular}

The sandy component existing in the inner dump of the North Pesteana quarry indicates a probability of occurence of the risk of liquefaction of the material under the conditions of its saturation.

Therefore, depending on the nature and structure of rocks in a rock mass or deposit and external or internal influences, the occurrence of sliding phenomena through liquefaction can be favored, a process by which the rocks lose their solid body properties and occurs the tendency to flow.

\subsubsection{Erosion}

Erosion is a natural process representing the dislocation and entrainment of material on the ground.

Local characteristics, such as the geomorphological configuration (slope height and slope angle), composition and structure of the rock massifs, hydrography and hydrogeology of the region, climate (especially from the pluviometric regime) and vegetal cover state, influence the degree of erosion.

The erosion phenomenon can be manifested on the quarry and inner dump slopes as a result of the superficial runoff of precipitation water. Erosion is one of the main causes of landslides as it leads to the appearance of channels that favor the infiltration of water into the rocks and the creation of minimal resistance surfaces, potential slide surfaces.

Several areas of erosion (generally gutters, so small channels) formed as a result of superficial rainwater leakage have been identified in the North Pesteana perimeter. [6]

In the case of flooding of the remaining gap of the North Pesteana quarry, so in the case of the creation of a quarry lake, the erosion of the banks - represented here by the definitive slopes of the quarry, occurs under the action of the waves, their formation being influenced by the wind and the atmospheric pressure variation. Thus, a cavity is formed in the rock 
massif/rock deposit and there is the risk of breaking the shore or sliding of the material above the cavity created.

In the post-closure period problems may arise as a result of erosion processes. Therefore, it is important to apply measures to reduce the erosion. The most technically and economically efficient measures are to ensure a proper slope angle, compacting them and building drainage systems. However, the waters of the lakes exhibit a hydrostatic pressure on the slopes, also having a positive action, acting as a support prism in the direction of the increase of the resistance forces.

\subsubsection{Abnormal settlement of the rocks}

Settlements are geotechnical phenomena that are manifested by the vertical movement of the rocks and the sinking of the lands. Settlemenets occur as a result of the rocks being deposited under the effect of their own weight or the existence of overloads or the elimination of the liquid or gaseous phase of the rock mass, which results in the occurrence of underground gaps.

Abnormal settlements occur under drainage conditions (natural or anthropic) of water from rock pores. This causes sudden or gradual sinking of the rocks from the roof of the created gap and causes deformation of rocks in the roof and deformation of the ground surface. [9]

So far, in the North Pesteana mining perimeter no phenomena of abnormal settlements have been recorded, taking into account the functioning of the dewatering systems, which could have influenced the occurrence of these types of geotechnical phenomena. Therefore, it can be considered that the abnormal settlements of the land in the perimeter and the adjacent areas of the North Pesteana area is almost null after stopping the dewatering systems and flooding the remaining gap.

\subsection{Effects of negative geotechnical phenomena}

The immediate effect of losing the balance of a slope is the breaking off or flow of an important volume of solid rock and its movement under the action of gravity. With this movement takes place partial or total destruction of buildings, urban networks, transport and communications networks on the sliding surface, as well as those in the sliding influence areas.

The main objectives in the adjacent areas of the North Pesteana mining perimeter are represented by the individual households and the agricultural lands belonging to the villages: Valea cu Apa, Pesteana de Jos, Hotaroasa, Urdari, Pesteana Jiu, Cocoreni and Balteni, plus natural land with pastures or forests, the Jiu River, numerous streams, the network of roads and others. They are at distances of about 50-100 m up to $1 \mathrm{~km}$ from the mining perimeter. Therefore, in case of negative geotechnical phenomena, the risks are significant and it is necessary to apply the necessary measures in order to reduce the risks which may occur in time.

In order to synthesize, as far as possible, the effects of landslides, the network method, recommended for the study of cause-effect relationships, was applied. [10] Thus, a network has been developed to identify the negative effects of geotechnical phenomena in the event of their occurrence at the definitive slopes of the North Pesteana quarry. "Action of the project" is replaced by a given situation: sliding of the definitive slopes. Three situations were considered, namely the identification of the effects of slide of the final slopes before the flooding, during the flooding and after the flooding of the remaining gap of the quarry (Figure 3 ). 
The multitude of devastating effects, already known and highlighted in this paper, has stimulated researchers and specialists to analyze the mechanisms of producing negative geotechnical phenomena taking into account all possible factors of influence in order to establish prevention and mitigation measures.

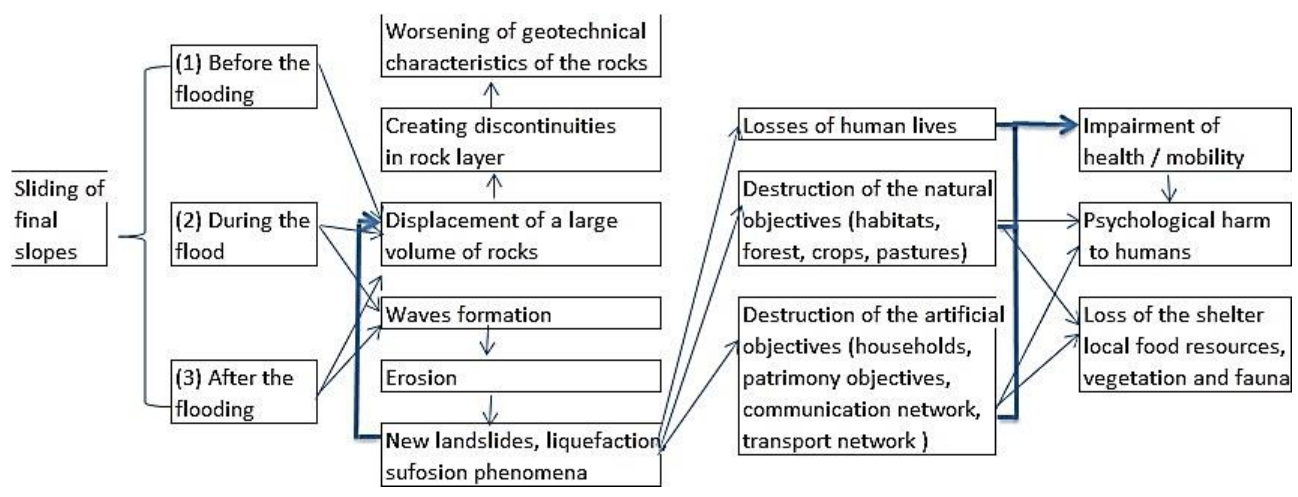

Fig. 3. Network for identifying the effects of geotechnical phenomena in the North Pesteana perimeter

\subsection{Measures to avoid the occurrence of negative geotechnical phenomena}

The stabilization of the final slopes of the remaining gaps can be achieved by using the appropriate engineering techniques to increase their stability.

In the case of the remaining gap of the North Pesteana quarry, given the possibility of the occurence of negative geotechnical phenomena, the following measures are recommended:

- removing of gutters, ravines, cracks and fissures by filling with material and leveling and compacting slopes and berms, especially those of the inner dump, since the material in the dump is loose;

- adequate drainage of surface water. Construction of surface drainage systems collecting and directing the water out of the zones of influence. This avoids the phenomena of pluvial erosion.

- controlling the inflow of water to the remaining gap. The dewatering works of the aquifer formations from the North Pesteana perimeter is carried out by natural drainage through the quarry's slope and by 4 drilling holes equipped with submersible pumps. After the mining activity ceases, to control the inflow of water that contributes to the flooding of the residual gap, it is recommended to maintain one or more of the existing dewatering drills.

- the design of the geometrical elements of the final slopes to provide a suitable stability reserve or to apply the measures to reduce the angle of the final slopes [11];

- revegetating of the degraded lands; Vegetation has a positive influence on stability as it anchors the topsoil and rocks by roots, prevents the occurrence of erosion phenomena, intercepts some of the precipitation water, captures the energy of rain drops, reduces surface velocity, acts as a filter that prevents sediment transport etc. It is advisable to reveal the platform of the 4th step of the quarry [11]. 


\section{Conclusions}

The presence of water in rock's pores influences the state of unitary effort by varying the humidity of rocks and changing their geotechnical characteristics. The flooding of the remaining gaps implies the saturation of the rocks from the final slopes of the quarry. Under these circumstances, the main geotechnical risks that may arise are: the risk of sliding of the in-situ slopes, the risk of liquefaction of the dumped material, the risk of occurrence of sufosis phenomena, other types of negative geotechnical phenomena (erosion, abnormal settlement of the rocks etc.).

In the case of the remaining gaps of the North Pesteana quarry, the large inflow of groundwater that will contribute to the restoration of the aquifer resources and the flooding of the gap may favor the phenomenon of sufosis on a higher scale than that observed during the activity period. The problem of liquefaction arises in the moment of saturation of the loose dumped material which contains important sand fractions and possibly in-situ sandy rocks, in the conditions of increased water pressure in rocks pores. Surface leakage and wave formation on the lake also favor erosion processes, resulting in the appearance of minimal resistance surfaces, potential sliding surfaces.

If, by the time of the complete flooding of the remaining gap of the North Pesteana quarry, no negative geotechnical phenomena arise, the possibility of their occurrence in the future decreases, as the hydrostatic pressure will act on the final slopes like a bearing prism.

Geotechnical phenomena have many negative effects. They may be devastating phenomena and are responsible for causing significant damage. Knowing the hydrogeological and geotechnical characteristics of the rocks, as well as the influence factors, allows the designing and dimensioning of stable definitive slopes and the geotechnical risks will be reduced or even eliminated.

\section{References}

1. E. Moraiti, B. Christaras, R. Brauer, Bulletin of the Geological Society of Greece, 43, 3 (2010)

2. Government of Romania, "Plan of the national territory development" (in Romanian) (Monitorul Oficial al Romaniei, 2001)

3. I. Rotunjanu, Slopes stability (in Romanian) (Infomin Publishing House Deva, 2005)

4. M. Stănciucu, Slopes stability (in Romanian), (Tehnical Publishing House Bucharest, 2018)

5. M. Lazar, Reports of Professorship Surface Mining, 63 (2017)

6. I. M. Apostu, M. Lazăr, F. Faur, Annals of the University of Petroşani, 19, 1 (2018)

7. http://www.bergbau.sachsen.de/download/Nachweis_der_Erforderlichkeit.pdf (accessed 12.02.2019)

8. ICSIT-PML, Report on environmental impact study, continuation of mining works in the license area for Peșteana Mining Quarry Unit - the North Peșteana quarry proposed to be located in the outbuilding/urban area of the Urdari, Bălteni and Plopssoru communes, Gorj County (in Romanian), (Romanian Institute of Scientific Research, Technological Engineering and Lignite Mine Designing, 2012)

9. F. T. Lee, J. F. Abel, Subsidence from underground mining: environmental analysis and planning considerations, Geological survey circular 876, (USGS, 1983)

10. M. Lazăr, I. Dumitrescu, The anthropic impact on the environment (in Romanian) (Universitas Publishing House Petroșani, 2006)

11. I. Apostu, F. Faur, Research Journal of Agricultural Science, 50, 4 (2018) 